\title{
Eulogy for the clinical research center
}

\author{
David G. Nathan ${ }^{1}$ and David M. Nathan² \\ 'Dana Farber Cancer Institute, Harvard Medical School, Boston, Massachusetts, USA. ²Diabetes Center and Clinical Research Center, Massachusetts General Hospital (MCH), Harvard Medical School, \\ Boston, Massachusetts, USA.
}

\begin{abstract}
The extramural General Clinical Research Center (CCRC) program has been funded for more than $\mathbf{5 0}$ years, first by the National Center for Research Resources, NIH, and more recently as part of the Clinical Translational Science Award (CTSA) program through the newly formed National Center for Advancing Translation Sciences (NCATS). The GCRCs represent the federally funded laboratories that employ a highly trained cadre of research nurses, dietitians, and other support staff and in which generations of clinical investigators trained and performed groundbreaking human studies that advanced medical science and improved clinical care. Without the opportunity for adequate discussion, NCATS has now stopped funding these Research Centers. In this "eulogy," we review the origins and history of the GCRCs, their contributions to the advancement of medicine, and the recent events that have essentially defunded them. We mourn their loss.
\end{abstract}

\section{Introduction}

The Clinical Research Center (CRC) program, supported by NIH extramural funding, is now dead (1). The CRCs included the only federally supported beds ( 600 nationwide) and outpatient human research "laboratories" in academic medical centers dedicated to support all clinical investigators. Until recently, the CRCs provided many services free of charge to federally funded investigators. Industry-initiated studies were charged for services provided.

Originally funded from the 1960s as the General Clinical Research Center (GCRC) program through the National Center for Research Resources (NCRR), support for CRCs became part of the Clinical and Translational Science Awards (CTSA) program in 2006, which was subsequently incorporated into the newly established National Center for Advancing Translation Sciences (NCATS) in 2011 (2, 3). Funding support for the CRCs began to be restricted by NCATS within several years of its creation. The eventual total defunding of the CRCs was carried out purportedly on the basis of Institute of Medicine (IOM) recommendations (4) and a subsequent NCATS Advisory Council
Working Group report (5), although neither report included any specific recommendations regarding the CRC program, and several members of the IOM Committee whom we contacted have denied any such intent. The defunding of the CRCs, the home of federally funded clinical research for more than 50 years, including the space that they occupy and their highly trained research staff, has occurred with virtually no discussion in the scientific community. As experienced CRC users and as the director of a GCRC/CRC for more than 25 years (D.M. Nathan), we mourn their loss and here present our eulogy.

\section{The role of clinical center investigation in \\ American medicine}

The history of research-oriented "beds" is actually the history of modern academic medicine. Less than a century ago, American medical schools were largely trade schools. Laboratory-based academic inquiry barely existed within them. Johns Hopkins, the University of Michigan, and the University of Pennsylvania had nascent academic programs that were carried out largely by pathologists. Amer- icans with a desire to learn the biomedical research technology of the early twentieth century were forced to travel to England, France, Austria, or Germany.

The first American hospital entirely devoted to clinical research was created at Rockefeller University in 1910, where a score or so of beds were surrounded by basic research laboratories. The hope was that basic science would create new technologies that would be explored at the bedside to understand and improve the prognosis of patients. Harvard Medical School copied the Rockefeller model when the ten-research bed "Ward 4" opened at MGH in 1925 (6). It was in those beds that Fuller Albright, the father of endocrinology in the US, studied hyperparathyroidism and its effective treatment. In the same decade, Francis Weld Peabody, a former MGH house officer, was recruited by Harvard Medical School to lead a larger clinical research enterprise, the Thorndike Memorial Laboratory and the Thorndike Research Ward at the then Boston City Hospital (7). He in turn recruited two other graduates of the MGH program, George Richards Minot and William Bosworth Castle, to join him. Minot and others received a Nobel Prize for their contributions to our understanding of the role of vitamin B12 deficiency in pernicious anemia. Castle is correctly considered one of the founders of modern hematology.

\section{Establishment of the intramural and extramural clinical research center programs by the $\mathrm{NIH}$}

Biomedical research success in the United States is the product of the interaction of three forces: the proper amalgam of basic and clinical biological research effort, together with advanced clinical care, within the academic biomedical community; the continued effort of profit-motivated pharmaceutical and biotechnical companies; and the overall support of the enterprise by the NIH and other members of the grant-making and donor com- 
munity. The directors of the NIH have had a profound influence on biomedical research in the United States. Lewis Thompson, the fifth director, secured the present NIH campus and built its first six buildings including the National Cancer Institute. Rolla Dyer, the sixth director, planned the Clinical Center, the NIH's central clinical research facility, and established the National Heart Institute and the National Institute of Mental Health. James Shannon, the eighth director (19551968), played a transformative role as he presided over the massive growth and influence of both the intra-and extramural programs of the NIH, including the initiation of the GCRC program. The GCRCs aimed to provide medical scientists "who receive their primary research funding from the other components of the NIH" with "the resources which are necessary for the conduct of clinical research" (3). Shannon's regime produced the eleventh (Donald Fredrickson), twelfth (James Wyngaarden), and fourteenth (Harold Varmus) directors.

The legendary transformation of biomedical research by Rockefeller University had a major effect on the intra- and extramural programs of the NIH. The planners of the original intramural NIH Clinical Center, which opened in 1953, reasoned that if Rockefeller could be successful with twenty research beds, the United States government could be even more successful with ten times as many. Each of the several NIH Institutes was assigned a proportional fraction of the new beds, with the National Cancer Institute and what became the National Heart Lung and Blood Institute holding the lion's share. The beds were on one side of the modern building, and research laboratories for investigators studying the patients filled the other side. A massive recruiting program produced a spectacular clinical and research faculty, and house staff to care for the patients came from the medical and surgical training programs of leading American medical schools. When those residents returned to their home medical schools, many became the academic division chiefs of the future, supported by a cornucopia of $\mathrm{NIH}$-derived research and training grants. In that golden age of the intramural $\mathrm{NIH}$ program, the contributions of the NIH Clinical Center to academic medicine could only be called extraordinary.

\section{Contributions of the GCRC program}

The first extramural GCRC grants from the NIH were awarded in 1963 to several leading teaching hospitals around the country. The grants provided stable support for the necessary research space, beds, and equipment to carry out experimental measurements and therapeutics in volunteer patients. The GCRCs included a highly trained, specialized staff of research nurses, coordinators, statisticians, research subject advocates, bioinformaticians, and bionutritionists, who reliably carried out complex research protocols from myriad investigators.

For the next 40 years, the contributions of the GCRCs to medical research were outstanding. Although endocrinology, nephrology, and metabolism were the major beneficiaries early on, as those fields particularly require careful measurements of body fluids that can only be well performed in a research environment, the GCRCs, and now CRCs, have served every discipline in medical science.

Physiologic and interventional studies and NIH-sponsored clinical trials that were performed at GCRCs revolutionized the understanding, prevention, and treatment of disease. A small number of examples emanating from the GCRCs at Rockefeller University and MGH (the first clinical research units in the country) include the following: advances in understanding the pathophysiology and treatment of heroin addiction with methadone (8); the establishment of highly active antiretroviral therapy (HAART) for HIV (9); the treatment of precocious puberty $(10,11)$ and bone disease associated with hyperprolactinemia, anorexia, and other reproductive disorders $(12,13)$; and the revolutionary results of intensive treatment of type 1 diabetes $(14,15)$ and prevention of type 2 diabetes (16). Each of these studies, some of them multicentered with collaborations among GCRCs around the country, relied on the resources supplied by the GCRCs. During this period, the profile of GCRC research turned increasingly to outpatient studies. While much of the cardiology and oncology clinical research could be conducted in the clinical space, intensive phenotyping, the testing of new medications, other types of interventions and diagnostic methods, and the uniform conduct of multicentered $\mathrm{NIH}$-sponsored studies have depended on the GCRC facilities and their expert staff. Moreover, young investigators with insufficient funds to build facilities and recruit and train their own staff to conduct their early work found a "rent-free" home in the GCRCs, as most of the infrastructure for clinical research was supported by the institutional GCRC grants.

\section{The death of the CRC}

Increasing concern regarding the decline in applications for NIH grants from aspiring research-oriented physicians during Wyngaarden's and Varmus' tenures led to the 1995 formation of a Directors Committee on Clinical Research (17). The 1995 committee (chaired by D.G. Nathan) advanced a broad definition of clinical research that included: (a) laboratory-based studies of patients and their biosamples and tissues; (b) studies in humans of mechanisms of disease, therapeutic interventions, and the development of new technologies; (c) clinical trials and epidemiologic and behavioral studies; and (d) outcomes and health services research (17).

The 1995 committee concluded that much of the aforementioned decline was based on both the financial and intellectual insecurity of physician applicants. Educational debt relief programs and $\mathrm{K}$ awards were therefore urged as essential for the MD graduates and young investigators who hoped to pursue clinical research careers. The committee also strongly advised the NIH to maintain the percentage of extramural clinical research support in the NIH budget at least at the level that was extant in 1998. This combination of initiatives would, the committee thought, produce higher success rates in R01 competitions, alleviate angst, and restore the physician clinical researcher pool of applicants. Importantly, the major recommendation regarding the GCRCs was: "The scope of the GCRCs should be broadened to enhance their leadership role in clinical research and research training and $\mathrm{NIH}$ should significantly increase its financial support of these centers" (17).

Elias Zerhouni, a radiologist with a strong interest in systems analysis, became the fifteenth NIH Director in 2000. He believed that clinical researchers were disaffected in part because they had inade- 
quate homes within the approximately 80 medical centers around the country with GCRCs and that the onrushing molecular revolution in medicine was rendering the old GCRC model superfluous. Zerhouni concluded that the GCRC program, as initially constituted, needed to be "consolidated" and more of its funds devoted to training, education, and collaboration (18). Thus was born the Clinical and Translation Science Award (CTSA) program. The GCRCs that survived were incorporated as one element in the CTSA "hubs" and were initially maintained. However, the most recent funding announcement (1) prohibits any direct funding for the CRC space or for the actual conduct of research studies and eliminates the vast majority of research nursing, nutrition, and other staff from the CRC, essentially destroying the human research laboratories in which thousands of investigators have performed their research. (The most recent request for application [RFA] notes: "CTSA funding can be used to support clinical research staff only for oversight and quality assurance, but not to support actual research activities that are part of studies and trials conducted at the CTSA hub ... Space to conduct research cannot be charged to the CTSA grant") (1).

Biomedical research is highly dependent on technology, and advances in molecular genetics, cell biology, and imaging have become increasingly important. These advances have to some extent swept the study of intact patients off center stage. The changes that Zerhouni initiated, with the inclusion of the extramural GCRC program at CTSAs that were shifting their emphasis to training and education, were continued by Francis Collins, a genetics clinical investigator who became the sixteenth Director of the NIH in 2008. To deal with clinical research and the plight of physician-scientists, he established a committee co-chaired by David Ginsburg and NIH staff. In 2014, that committee confirmed the troubles of physician-scientists and made several valuable recommendations. Like the 1995 committee, the Ginsburg committee made no suggestions to defund the CRCs (19).

With little, if any, public discussion, the Collins administration decided to eliminate any direct funding for the CRCs and converted the CTSAs into what is now essentially a training program and a network of "hubs" that might interact on clinical trials of mutual interest. Gone are the beds and research space, the patients in the beds, the novel ideas to be tested at the bedside and in outpatient CRCs, and the brilliant nurses and other support team members who made it all happen. None of the committees that have advised the Director, not the original IOM Committee (4), the Advisory Council reporting on the IOM report (5), or the Advisory Committee to the Director (ACD) on NCATs chaired by Maria Freire, $\mathrm{PhD}$, which met three times in 2011 (20), has ever mentioned, much less suggested, defunding the CRCs. And yet, they are now effectively gone.

The current narrative of clinical research has been simplified into a dichotomy of large database exploration, such as GWAS, or clinical trials that are largely left to industry. However, the traditional role played by the GCRCs and CRCs, such as the deep phenotyping necessary to understand disease processes and complement genetic, proteomic, metabolomic, and imaging studies, is arguably more important than ever. Similarly, trials that are important to the advancement of the public health mission of the NIH, such as comparative effectiveness studies and other patient-centered research not performed by pharmaceutical companies, also need a home. Bench-to-bedside studies, first-inhuman trials that effectively join academic bench investigators and their clinical research colleagues, may be performed most effectively and efficiently in CRCs. Finally, young investigators who wish to conduct clinical research projects during their formative years continue to rely on the CRCs for training opportunities.

We mourn the loss of the CRCs, because we know how hard it is to create well-functioning research facilities. Only highly trained nurses and other specialists have the skills and the interest to carry out refined research procedures. The careful measurement of human physiology and disease processes and the implementation of complex, novel interventions simply cannot be performed well - or at all - in the inpatient or outpatient clinical setting. Once the CRC research nurses and other research colleagues are gone and the facilities are "repurposed," it will take years to replace and rebuild them, respectively, even if the NIH reverses course and brings back the CRCs.

We fear that the decision to defund the CRCs, made without any public discourse, will deeply damage clinical research and demoralize the clinical research community. As the CRCs slip away, we deeply mourn their loss.

\section{About the authors}

D.G. Nathan and D.M. Nathan have been funded continually by NIH grants and clinical research centers since 1963 and 1980, respectively. D.M. Nathan has also served as the Director of the Mallinckrodt GCRC at MGH from 1990 to 2008 and as the Director of the MGH CRC, part of the Catalyst Clinical Translational Science Center at Harvard Medical School, since 2008.

\section{Acknowledgments}

The authors are grateful to many colleagues, particularly Barry Coller, David Ginsburg, Garret Fitzgerald, and David Williams, for their incisive comments, and for the continued support of the NIH throughout the authors' careers.

Address correspondence to: David G. Nathan, Dana 1644, Dana-Farber Cancer Institute 450 Brookline Avenue, Boston, Massachusetts 02215, USA. Phone: 617.632.2155; E-mail: david_nathan@dfci. harvard.edu.

1. National Center for Advancing Translational Sciences; NIH. Department of Health and Human Services, Clinical and Translational Science Award (U54). https://grants.nih.gov/grants/ guide/rfa-files/RFA-TR-14-009.html. Published September 12, 2014. Accessed May 13, 2016.

2. CTSA Principal Investigators, et al. Preparedness of the CTSA's structural and scientific assets to support the mission of the National Center for Advancing Translational Sciences (NCATS). Clin Transl Sci. 2012;5(2):121-129.

3. Robertson D, Williams GH, eds. Clinical and Translational Science Infrastructure in Clinical and Translational Research: Principles of Human Research. 1st ed. London, United Kingdom: Academic Press; 2009.

4. Committee to Review the Clinical Translational Science Awards Program at the National Center for Advancing Translational Sciences; Board on Health Sciences Policy; Institute of Medicine, authors. Leshner AI, Terry SF, Schultz AM, Liverman CT, eds. The CTSA Program At NIH. Opportunities For Advancing Clinical And Translational Research. Washington, DC, USA: The National Academies Press; 2013

5. Working Group of the NCATS Advisory Council to the Director. NCATS Advisory Council 
Working Group on the IOM Report: The CTSA Program at NIH. https://ncats.nih.gov/files/ CTSA-IOM-WG-draft-report.pdf. Published May 16, 2014. Accessed May 13, 2016.

6. Means JH. Ward 4-the Mallinckrodt Research Ward of the Massachusetts General Hospital. Cambridge, Massachusetts, USA: Harvard University Press; 1958.

7. Elrod JM, Karnad AB. Boston City Hospital and the Thorndike Memorial Laboratory: the birth of modern haematology. Br J Haematol. 2003;121(3):383-389.

8. Dole VP, Nyswander M. A medical treatment for diacetylmorphine (heroin) addiction. A clinical trial with methadone hydrochloride. JAMA. 1965;193:646-650.

9. Markowitz M, et al. The effect of commencing combination antiretroviral therapy soon after human immunodeficiency virus type $1 \mathrm{infec}-$ tion on viral replication and antiviral immune responses. J Infect Dis. 1999;179(3):527-537.

10. Comite F, Cutler GB, Rivier J, Vale WW, Loriaux DL, Crowley WF. Short-term treatment of idiopathic precocious puberty with a long-acting analogue of luteinizing hormone-releasing hormone. A preliminary report. $N$ Engl J Med. 1981;305(26):1546-1550.

11. Mansfield MJ, et al. Long-term treatment of central precocious puberty with a long-acting analogue of luteinizing hormone-releasing hormone. Effects on somatic growth and skeletal maturation. N Engl J Med. 1983;309(21):1286-1290.

12. Klibanski A, Neer RM, Beitins IZ, Ridgway EC, Zervas NT, McArthur JW. Decreased bone density in hyperprolactinemic women. $N$ Engl J Med. 1980;303(26):1511-1514.

13. Klibanski A, Greenspan SL. Increase in bone mass after treatment of hyperprolactinemic amenorrhea. N Engl J Med. 1986;315(9):542-546.

14. [No authors listed]. The effect of intensive treatment of diabetes on the development and progression of long-term complications in insulin-dependent diabetes mellitus. The Diabetes Control and Complications Trial Research Group. NEnglJ Med. 1993;329(14):977-986.

15. Purnell JQ, Zinman B, Brunzell JD, DCCT/EDIC Research Group. The effect of excess weight gain with intensive diabetes mellitus treatment on cardiovascular disease risk factors and atherosclerosis in type 1 diabetes mellitus: results from the Diabetes Control and Complications Trial/Epidemiology of Diabetes Interventions and Complications Study (DCCT/EDIC) study. Circulation. 2013;127(2):180-187.

16. Knowler WC, et al. Reduction in incidence of Type 2 diabetes with life-style intervention or metformin. N Engl JMed. 2002;346(6):393-403.

17. Executive Summary - NIH Director's Panel on Clinical Research Report 12/97. http://grants. nih.gov/grants/NIH_Directors_Panel_Clinical_ Research_Report_199712.pdf. Accessed May 13, 2016.

18. Zerhouni EA. Translational and clinical science - time for a new vision. $N$ EnglJMed. 2005;353(15):1621-1623.

19. NIH. Physician-Scientist Workforce Working Group Report. http://acd.od.nih.gov/reports/ psw_report_acd_06042014.pdf. Published June 1, 2014. Accessed May 13, 2016.

20. Freire M, et al. ACD Working Group Activities: National Center for Advancing Translational Sciences. Summary of Findings. http://acd. od.nih.gov/reports/ACD-NCATSWGR 09212011.pdf. Published September 21, 2011. Accessed May 13, 2016. 